Marília Paula e Silva

Aplicação de Redes Neurais Artificiais no Diagnóstico de Falhas de Turbinas a Gás

Dissertação apresentada como requisito parcial para obtenção do título de Mestre pelo Programa de PósGraduação em Engenharia Mecânica da PUC-Rio.

Orientador: Prof. Sergio Leal Braga Co-orientador: Dr. Sandro Barros Ferreira 
Marília Paula e Silva

\section{Aplicação de Redes Neurais Artificiais no Diagnóstico de Falhas de Turbinas a Gás}

Dissertação apresentada como requisito parcial para obtenção do título de Mestre pelo Programa de Pós-Graduação em Engenharia Mecânica da PUC-Rio. Aprovada pela Comissão Examinadora abaixo assinada.

Prof. Sergio Leal Braga

Orientador

Departamento de Engenharia Mecânica - PUC-Rio

Dr. Sandro Barros Ferreira

Co-orientador

GT2 Energia

Prof. Paulo Smith Schneider

Departamento de Engenharia Mecânica - UFRGS

Prof. a Marley M. B. Rebuzzi Vellasco

Departamento de Engenharia Elétrica - PUC-Rio

Prof. José Alberto dos Reis Parise

Departamento de Engenharia Mecânica - PUC-Rio

Prof. José Eugênio Leal

Coordenador Setorial do Centro Técnico Científico - PUC-Rio

Rio de Janeiro, 26 de abril de 2010 
Todos os direitos reservados. É proibida a reprodução total ou parcial do trabalho sem autorização da universidade, da autora e do orientador.

\section{Marília Paula e Silva}

Graduou-se em Engenharia Mecânica pela Pontifícia Universidade Católica do Rio de Janeiro - PUC-Rio, em 2006.

Ficha Catalográfica

Silva, Marília Paula e

Aplicação de Redes Neurais Artificiais no Diagnóstico de Falhas de Turbinas a Gás / Marília Paula e Silva; orientador: Sergio Leal Braga; co-orientador: Sandro Barros Ferreira. - Rio de Janeiro: PUC, Departamento de Engenharia Mecânica, 2010.

107 f.: il. (color.); $30 \mathrm{~cm}$

Dissertação (mestrado) - Pontifícia Universidade Católica do Rio de Janeiro, Departamento de Engenharia Mecânica, 2010.

Inclui bibliografia.

1. Engenharia Mecânica - Teses. 2. Redes Neurais Artificiais. 3. Diagnóstico. 4. Turbinas a Gás. I. Braga, Sergio Leal. II. Ferreira, Sandro Barros. III. Pontifícia Universidade Católica do Rio de Janeiro. IV. Departamento de Engenharia Mecânica. VI. Título. 
Aos meus pais, meus exemplos de vida e grandes incentivadores desta conquista. 


\section{Agradecimentos}

A Deus que me guiou e deu forças durante toda esta jornada.

Aos meus pais, João Cândido e lára, e às minhas irmãs, Elisa e Lucila, pelo apoio, amor e cumplicidade, sem os quais seria impossível a realização deste trabalho, minha eterna gratidão.

Meu agradecimento especial ao Felipe, que muito mais que namorado, foi companheiro, amigo e grande incentivador em todos os momentos.

Ao Dr. Sandro Barros Ferreira pelo incentivo, orientação e ensinamentos transmitidos ao longo o desenvolvimento deste trabalho.

Ao Professor Sergio Leal Braga pela confiança depositada.

À PUC-Rio pelo auxílio concedido.

Ao Departamento de Engenharia Mecânica da PUC-Rio pela oportunidade.

À Paula, à Cláudia e ao Rafael pela amizade e apoio.

Ao Vinícius pela amizade, paciência e ajuda no decorrer deste trabalho.

A toda equipe GT2 Energia $e$ a todos os amigos pelo incentivo e companheirismo sempre presentes, meus sinceros agradecimentos. 


\section{Resumo}

Paula e Silva, Marília; Braga, Sergio Leal. Aplicação de Redes Neurais Artificiais no Diagnóstico de Falhas de Turbinas a Gás. Rio de Janeiro, 2010. 107p. Dissertação de Mestrado - Departamento de Engenharia Mecânica, Pontifícia Universidade Católica do Rio de Janeiro.

A deterioração do desempenho da turbina a gás é resultado de vários tipos de falhas, como acúmulo de sujeira, erosão e corrosão, que afetam os componentes no caminho do gás, sendo os principais o compressor, o combustor e a turbina. No presente trabalho é avaliado o desempenho de Redes Neurais Artificiais (RNA) no emprego de diagnóstico de falha de turbinas a gás. Todas as redes projetadas são do tipo MLP (multi-layer perceptron) com algoritmo de retropropagação (backpropagation). Para cada função de diagnóstico, várias arquiteturas foram testadas, modificando parâmetros de rede como o número de camadas escondidas e o número de neurônios em cada uma destas camadas. As RNAs para diagnóstico de falhas foram aplicadas ao modelo termodinâmico de uma turbina a gás industrial. Este modelo foi responsável pela criação de dados da usina saudável e também degradada, utilizados para o treinamento e validação das redes. Com os resultados obtidos do treinamento das redes é possível mostrar que as mesmas são capazes de detectar, isolar e quantificar falhas de componentes de turbinas a gás de forma satisfatória

\section{Palavras-chave}

Redes Neurais Artificiais; Diagnóstico; Turbinas a Gás. 


\section{Abstract}

Paula e Silva, Marília; Braga, Sergio Leal (Advisor). Artificial Neural Networks Applied to Gas Turbine Fault Diagnostics. Rio de Janeiro, 2010. 107p. MSc. Dissertation - Departamento de Engenharia Mecânica, Pontifícia Universidade Católica do Rio de Janeiro.

The gas turbine performance deterioration is a result of several types of faults such as fouling, erosion and corrosion, which affects the components throughout the gas path. As the most significant of these components we can enumerate the compressor, the combustion chamber and the turbine itself. In this work the performance of different types of Artificial Neural Networks (ANN) are evaluated in the diagnosis of this kind of fault. Every neural network designed in this work is MLP (multi-layer perceptron) with back propagation algorithm. For each diagnosis function several architectures were tested, varying network parameters as the numbers of hidden layers and the number of neurons in each layer. The ANNs for fault diagnosis were applied in an industrial gas turbine thermodynamic model. This model was also used for healthy and degraded turbine data generation, which were used for ANNs training and validation. With the ANNs training results we can conclude that these networks are capable of detecting, isolating and quantifying gas turbine components faults in a satisfactory way.

\section{Keywords}

Artificial Neural Network; Diagnostic; Gas Turbine. 


\section{Sumário}

1 Introdução 16

1.1. Objetivo 17

1.2. Estrutura do Trabalho 17

2 Revisão Bibliográfica 18

2.1. Degradação do Desempenho da Turbina a Gás 18

2.2. Falhas no Caminho do Gás 18

2.2.1. Índices de Falhas no Caminho do Gás 20

2.3. Métodos de Diagnóstico Baseados na Análise do Caminho do Gás 21

2.3.1. Árvore de Falhas 22

2.3.2. Análise do Caminho do Gás: Modelo Linear 22

2.3.3. Análise do Caminho do Gás: Modelo Não-Linear 24

2.3.4. Algoritmos Genéticos 24

2.3.5. Sistemas Especialistas 25

2.3.6. Redes Neurais Artificiais 26

2.4. Estado da Arte $\quad 27$

3 Redes Neurais Artificiais 33

3.1. Introdução 33

3.2. O Modelo do Neurônio Artificial 33

3.3. Tipos de Redes Neurais $\quad 36$

3.3.1. Redes Multilayer Perceptron (MLP) 38

3.4. Algoritmos de Treinamento 39

3.4.1. Algoritmo de Retropropagação 40

3.5. Desempenho de uma RNA 41

4 O Modelo Termodinâmico da Turbina a Gás 43

4.1. Introdução 43

4.2. Desempenho no Ponto de Projeto 44

4.3. Desempenho Fora do Ponto de Projeto 46

4.4. Degradação do Desempenho 47 
5 RNA para Diagnóstico de Falhas em Turbinas a Gás 49

5.1. Introdução $\quad 49$

5.2. O Modelo de Diagnóstico 49

5.3. O Projeto das Redes Neurais 51

5.4. Treinamento e Validação das Redes Neurais 52

5.4.1. Redes Neurais para Classificação de Falhas 52

5.4.2. Redes Neurais para Quantificação de Falhas 56

5.5. Teste das Redes Neurais 58

5.6. Discussão dos Resultados 58

6 Conclusões $\quad 64$

6.1. Sugestões para Trabalhos Futuros 66

$\begin{array}{ll}7 \text { Bibliografia } & 67\end{array}$

Apêndice A DESTUR (Desempenho de Turbinas) 71

Apêndice B Modelagem Termodinâmica do Desempenho de Turbinas a Gás 78

Apêndice C Resultado do Treinamento e Validação 103 


\section{Lista de Figuras}

Figura 1 - Comparação dos métodos de diagnóstico em termos de velocidade de processamento e complexidade do modelo [5]. 28

Figura 2 - Ferramenta de diagnóstico baseado em MLP [15]. 30

Figura 3 - Modelo matemático do neurônio de uma RNA [19]. 34

Figura 4 - (a) Função limiar, (b) Função limiar por partes e (c) Função sigmóide com parâmetro de inclinação a variável. 35

Figura 5 - llustração do treinamento de uma RNA. 37

Figura 6 - Redes com propagação progressiva de uma camada $\begin{array}{ll}\text { (perceptron). } & 37\end{array}$

Figura 7 - Rede do tipo MPL [19]. 38

Figura 8 - Método da para antecipada com conjunto de validação [9]. 42

Figura 9 - Esquema representativo de uma turbina a gás industrial. 44

Figura 10 - Efeito da variação da temperatura ambiente em relação ao ponto de projeto. 46

Figura 11 - Efeito da degradação do compressor no desempenho da turbina a gás. $\quad 48$

Figura 12 - Diagrama hierarquia das redes neurais estudadas. 50

Figura 13 - Desempenho das redes de classificação em função da taxa de acerto.

Figura 14 - Desempenho das redes de quantificação em função do desvio padrão do erro.

Figura 15 - Assinatura de falha do compressor (2\% de queda na eficiência isentrópica e $4 \%$ de queda no coeficiente de vazão).

Figura 16 - Assinatura de falha combinada do compressor e da turbina ( $2 \%$ de queda na eficiência isentrópica do compressor, $4 \%$ de queda no coeficiente de vazão do compressor, $0,5 \%$ de queda na eficiência isentrópica da turbina e $0,5 \%$ de queda no coeficiente de vazão da turbina).

Figura 17 - Ilustração da configuração adotada para simular a turbina a gás industrial.

Figura 18 - Ciclo simples de turbina a gás - configuração padrão.

Figura 19 - Razão combustível/ar teórica em função da temperatura de entrada e saída da câmara de combustão para combustível $\mathrm{C}_{8} \mathrm{H}_{18}$, 
considerando combustão completa sem perda de calor da câmara de combustão [30].

Figura 20 - Pás do estator e do rotor de uma turbina do primeiro estágio em corte ilustrando o sistema de resfriamento [30].

Figura 21 - Massa de ar para resfriamento versus a razão de temperatura [30].

Figura 22 - Esquema das regiões de resfriamento da turbina [30].

Figura 23 - Mapa de operação do compressor de uma turbina a gás Razão de pressão como função da velocidade de rotação e da vazão mássica na entrada do compressor.

Figura 24 - Mapa de operação do compressor de uma turbina a gás Eficiência como função da vazão mássica e da velocidade de rotação. 100 Figura 25 - Procedimento de cálculo para turbinas a gás operando fora do ponto de projeto. 


\section{Lista de Tabelas}

Tabela 1 - Valores de desempenho do modelo da turbina a gás industrial estudado. 43

Tabela 2 - Principais parâmetros utilizados no modelo termodinâmico. 45

Tabela 3 - Comparação entre os dados da simulação da turbina a gás e os dados do fabricante. 45

Tabela 4 - Seleção de parâmetros de entrada das RNAs. 52

Tabela 5 - Os limites da RDF. 53

Tabela 6 - Melhor resultado do treinamento e da validação da RDF. $\quad 54$

Tabela 7 - Desempenho das RNA de classificação. 55

Tabela 8 - Melhor resultado do treinamento e da validação da RDC. 57

Tabela 9 - Resultado dos testes para cada tipo de função de RNA estudado. 58

Tabela 10 - Lista de símbolos dos parâmetros apresentados nas Figuras 16 e 17.

61

Tabela 11 - Resultado do treinamento e da validação da RDF. 103

Tabela 12 - Resultado do treinamento e da validação da RIF. 104

Tabela 13 - Resultado do treinamento e da validação da RC_FS. 104

Tabela 14 - Resultado do treinamento e da validação da RDC. 105

Tabela 15 - Resultado do treinamento e da validação da RDT. 106

Tabela 16 - Resultado do treinamento e da validação da RD_CT. 107 


\section{Lista de Abreviaturas}

DESTUR - Programa de Desempenho de Turbinas a Gás

DOD - Dano por Objeto Doméstico (Domestic Object Damage)

ES - Sistema Especialista (Expert System)

FC - Falhas Combinadas dos Componentes

FCM - Matriz de Coeficientes de Falha (Fault Coefficient Matrix),

FOD - Dano por Objeto Estranho (Foreign Object Damage)

FS - Falhas Simples dos Componentes

FTA - Análise de Árvore de Falha (Fault Tree Analysis)

GPA - Análise do Caminho do Gás (Gas Path Analysis),

ICM - Matriz de Coeficientes de Influência (Influence Coefficient Matrix)

ISA - Atmosfera Padrão Internacional

MLP - Rede Multilayer Perceptron

MSE - Erro Médio Quadrático (Mean Square Error)

$\mathrm{PCl}$ - Poder Calorífico Inferior

PNN - Redes Neurais Probabilísticas (Probabilistic Neural Network)

RC_FS - Rede de Classificação de Falhas Simples

RD_CT - Rede da Degradação Concomitante do Compressor e Turbina

RDC - Rede de Quantificação da Degradação do Compressor

RDF - Rede de Detecção de Falhas

RDT - Rede de Quantificação da Degradação da Turbina

RIF - Rede de Isolamento de Falhas

RNA - Redes Neurais Artificiais

SFC - Consumo Específico de Combustível

SOM - Redes Auto-Organizáveis (Self-Organizing Map) 


\section{Lista de Símbolos}

A - Área

a - Parâmetro de Inclinação da Função de Ativação

C - Velocidade

$\mathrm{C}_{\mathrm{P}}-$ Calor Específico a Pressão Constante

$\mathrm{C}_{\mathrm{V}}$ - Calor Específico a Volume Constante

f - Razão Ar/Combustível

g - Aceleração da Gravidade

$\mathrm{h}-$ Entalpia

M - Número de Mach

$\dot{m}$ - Vazão Mássica

N - Rotação

P - Pressão

$\dot{Q}$ - Taxa de Transferência de Calor

$r$ - Raio Médio do Rotor

R - Constante Universal dos Gases

T - Temperatura

$U$ - Velocidade Tangencial

$\mathbf{w}_{\mathrm{kj}}-$ Pesos Associados às Sinapses

$\dot{w}$ - Trabalho Específico Útil

$x_{j}-$ Entrada da rede

$\mathrm{y}_{\mathrm{k}}$ - Saída da Rede

z - Altura 


\section{Subscritos e Letras Gregas}

$\eta$ - Eficiência de um Processo

$\Omega$ - Efetividade de Resfriamento

$\theta_{k}-$ Limiar da Rede (Bias)

$\rho$ - Densidade do Fluido

$\Sigma$ - Combinador Linear da Saída

$\varphi$ - Função de Ativação

$\Phi$ - Vazão Mássica Adimensional

Ф' - Coeficiente de Vazão

$\Psi$ - Rotação Adimensional

$\Psi$ ' - Rotação Semi-Dimensional 